... she is outside, she gets herself a key and

a front door where she can come and go, she

can do as she pleases, she can smile and talk,

meet other people, there is air and

possibilities

and only now is the house behind the walls a shelter, not a prison to Little Red Riding Hood.

The Wolf does not like this at all, he retaliates, he threatens, but it is a question of Little Red Riding Hood's life and she can not care about the Wolf's threats, and when Wolf notices it has no effect he falls silent.

So unnecessary. So unnecessary to quarrel about a little bit of air.

Thinks Little Red Riding Hood.

(Märta Tikkanen: Punahilkka, 279-280)

\title{
PERSISTENCE AND CHANGE OF GENDERED PRACTICES
}

Tuula Heiskanen and Liisa Rantalaiho

Our book has tried to make several aspects visible: the practices that maintain gendering processes on work places and in the society at large, the practices of living and acting in gendered social relations, potential or actual breaking points in established practices and structures, and the difficulties people may face trying to change gendered practices. We have introduced cases which, depending on the readers' frame of reference, may seem either as encouraging or discouraging examples. They point both to great durability and to potential for change in the gendered practices.

The empirical cases started with the problems of hierarchy. Quite often "gendered" means a hierarchical difference between men and women, the masculine and the feminine, with men and masculinity in the dominant position. This difference is quite strong in working life, also in a context where gender equality is an acknowledged ideology.

The importance of gender in workplace power relations varied quite a lot between different work places. But we never found a work place where women's and men's tasks and positions were not differentiated, or where the organizational goal would have been the de-construction of gendered hierarchies. And yet the picture is not one of a uniformly gloomy gender repression either.

Gendered hierarchies are not always visible or audible on work place level. It is rather rare in the Western part of the globe that a researcher can point to direct discrimination of women. Instead the construction of women's hierarchically lower positions is a delicate practice in which women or men mostly do not intentionally indulge. 
Gender is constructed on the work places in the daily work process and it is involved in solutions on how to organize the work. Some jobs and tasks almost unnoticeably become defined as feminine and others as masculine.

The definition of qualifications are central to the process of construction and maintenance of working life hierarchies. We could see deep cultural roots in the definitions of women's and men's work and women's and men's action spaces. However, the consequences in professional autonomy are dramatically different depending on whether the gender distinctions are flexible or strictly dichotomous. When women in organizations acquire their own professional space to work, gender hierarchies do not feel strong to them. Women see and appreciate their possibilities to develop their own work, even when it is not reflected in their wages. But when work is organized or managed so that men control women's work, gender hierarchies are strong and the situation is open for conflicts.

Gendered practices may be global, like some management ideologies or uses of information technology, and they may be simultaneously local and situational. A typical feature of hierarchical gender differentiating practices is an intertwining of several factors rather than a simple cause-effect relation. So, for example, the relation between statistical categories, collective agreement practices and work place action is circular - but indeterministic. The circular process includes both mutually reinforcing process chains and unpredictable points. Therefore a strictly gendered hierarchical 'iron cage' may coexist together with an easy indifference towards it.

We have considered work as one area in the everyday totality. This fits together with women's common sense understanding but contrasts with the prevailing organisational ideal of an abstract worker. But neither women's nor men's life in the context of our studies is limited to just working life or to just family. Nobody, or rather: no body lives exclusively within one 'sphere'. Working life and family overlap in people's experience, and it is time they should overlap also in both theoretical and organisational thinking.

We have talked about a person's life totality in the sense that it is something she actively constructs, 'quilts together' as Laura Balbo has expressed it (1987), so that the fragments of her life make a pattern. However, she does that in an inherently tense situation, constrained on the one hand by this organisational idea of an abstract worker, on the other hand by the realities of her everyday life which demand practical solutions. Whatever their occupation or branch of employment, women encounter this tension more often than men when they try to reconcile the demands of work and family. The division of labour between men and women in the families has long traditions, and changes are slow in this area - but they exist.

We also found that motherhood and fatherhood at work gives women and men differing premises to construct their everyday pattern, since organizations in working life recognize parenthood in a varying degree. Workplaces differed in how much flexibility and understanding of family demands they exhibited and how great a burden the combining of work and family therefore made for the workers. It is also interesting to note that both women and men make femininity visible at the work places, women with a greater cultural freedom and imagination, and men often quite stereotypically. Masculinity, instead, is seldom discussed, except when a man breaks the usual pattern of action, for instance using his part of the parental leave. 
A special impulse to focus on gendered practices was given by our wish to see how the existence of gendered divisions can be as fixed as it seems to be. Are there no breaking points in the persistency? One central difficulty is that change in itself may contribute to the persistency of gendered hierarchies. Working life is constantly changing before our eyes: new technological practices appear, organizational structures are reorganized, and employment relations diversify. But does gender change? We are now 'doing gender' differently from our mothers, but are we still doing basically the same kind of gender? Many visible gender relations in working life have indeed changed - and yet remained basically the same. For example, a profession may become feminized and all the while a new gendered division of labour and prestige develops within its frame. Women learn to master information technology but that does not alleviate the masculine closure of its expert culture. When new criteria for qualifications and wages are collectively adopted in female branches, men's wages there are increasingly paid on individual criteria. 'The more things change, the more they stay the same', and like the Red Queen in Alice's Adventures, women have to run hard to stay in the same place.

We have also analysed how the problems created by gendered practices are recognized and become objects of reform, from the perspective of both collective and individual actors. Many of our interviewees recognized gender discriminatory practices and inequality, for instance wage inequality, only in the society at large, but not on their own work place. Some thought that the well-known gender differences of social positions are natural, or consequences of individual choice, not a social issue. The daily practices which result in differing treatment and different positions for women and men were not recognized.

The Nordic countries have had a pioneering role in many legislative and social policy measures which unquestionably have improved the social position of women. The ideology of equality is strong - in a way everybody supports it. Considering this, it may seem paradoxical how difficult it was in our case studies to take up equality as a practical problem in the work places. This had many aspects: sometimes the problems had to do with power, sometimes with a lack of language.

In the case of comparable worth, a tentative understanding of the problem area was achieved relatively easily, but in the process of a closer definition of the problem, the situation turned to a power struggle. The arguments of women activists based on women's interests in a 'gender frame' were not as acceptable to the men in power as a 'general justice' frame. In school the researcher had difficulties convincing the teachers that any gender problem existed: the idea that their teaching could have any connection with labour market gender segregation seemed abstract and alien to them.

The researcher's participative role was an important element in several of our studies. In some of them the researchers held key roles as change agents, they kept up the discussion and brought to it concepts that could be used to analyse the situation. In the case of sexual harassment, the victim could analyse the problem only after it was given a name, she would have been lonelier and more confused with her experienced indignity without the researcher's concept that connected her to the group of other harassed women. The researchers' own expertise was an indispensable part of the change projects. The development and use of the job evaluation method, a basic tool of the comparable worth strategy, requires a certain technical expertise, and so does the teaching of computer programmes. In the information technology study circle, the situation could be analysed when the researcher gave the keys to an unfamiliar language. In the schools, the change project would hardly have started without an outside impulse, considering the defensive orientation of the teachers towards the project's ideas. 
The relationship between expertise and the grass root level has its problems. That is the case even when the researcher herself may be ideologically committed to women's empowerment, as in the information technology study circle, or to opening a door for new action possibilities, as in the desegregation project. We could get a glimpse from the other side of the situation. In the school the project was introduced top-down through an outside command and its basic ideas seemed contradictory to the teachers' own thinking. The teacher's opposition against the change project was twisted around the question: whose project is this? The researcher had quite a task to convince them that it could also be their own project.

The comparable worth project was in its starting phase emphatically a women's action. It was accommodated to become a project of the labour market parties, with all the concomitant achievements and sacrifices that such an argumentative terrain could give and demand. The backside of the technical expertise which maintained the process was the danger that women activists might lose their own voice to the altar of 'objective knowledge'. The problematic of women's own definitions and textuality in working life organizations is very complex. It seems that women need to develop their mutual support accordingly, to prevent their subjectivities from disappearing within the textualities, to make a balance between experiences and texts, in their own terms.

The local context of gendered practices turns out to be crucially important for change. And here we should count both the macro- and the micro-level of the local. The desegregation project for instance showed that if you want to change gendered practices, results are possible provided you get to the source where the practices emerge - and provided you do it anew in each location. Diffusion of change does not automatically take place even when the macro-level would favour it, because cultural resistance takes place on the micro-level.

Just as it can be difficult to recognize gendered practices when we ourselves live among them, to recognize change also requires systematic attention. It may be easier to look far than close. Looking back a couple of decades, we can often recognize big changes brought about by countless anonymous women and men who decide to live differently, for instance in new family forms. Instead it is hard to put in a proper perspective the changes that are presently taking place - for example, will mass unemployment change gender relations? What will be the relevance of the European Union to gendered practices in the member countries? Whether the practice is rooted in local or global, often textually mediated practices, it is essential for a change project to take into account what meanings and definitions the people involved in the practices attribute to them in the specific context where they live and act.

Considering the difficulties of intentionally changing gendered practices we could abstract two major problems of cultural definitions. One is the 'naturalization' of gender and gendered hierarchies, another is the attempt at gender neutrality in the spirit of an-already-achievedequality. In our local cultural and national context those two aspects are closely intertwined. They are often unintentional ways of producing persistence of gendered hierarchies and a resistance to change them - though of course naturalization of gender may also serve as a conscious resistance or backlash strategy.

The construction of gender is entangled in many processes. Persistence in itself is a problem, because all constancy reproduces itself as 'naturalness', as the unquestioned and unquestionable way of being. One side of that coin is that you gain cultural competence: you know automatically how to act and react. The other side is being shut inside the invisible walls of your local culture. Naturalization of gender has the consequence that the cultural walls close up. After that people 
no longer see the walls. Are fishes conscious of the water in which they swim? People in organizations quite often are not conscious of that their practices are gendered because they take them for granted. What else could be done, how else could they behave? Or they consider gender as a discourse on general social injustice, not something that relates to their own everyday life at work.

The practices which differentiate between women's and men's activities naturalize the gender hierarchy in the world of wage work. But so do the practices which tend to hide the difference. The seeming gender neutrality and the ideology of equality produce the very same hierarchy. The idea of gender neutrality proposes that gender should not be considered in some context because to do so would be either gender partial or detrimental to gender equality, that things 'should have nothing to do with gender', with the implicit argument that equality already prevails between women and men. But actually the neutrality idea is a great obstacle to sensitivity, and produces gendered consequences.

We would like to take the idea of gender neutrality a little further, to introduce the term of 'gender disabilities'. Not, however, in the meaning that it is women as a group or individuals who would be the disabled as the subordinated gender category. On the contrary, it is the organizations in working life that have the gender disabilities. Like the three apes of the story who do not see, hear or speak evil, many people in organizations refuse to see, hear or speak about gender. Organizations and people suffer from gender blindness: they will not see gender where it fills the scene. They suffer from gender deafness: they cannot hear gender where it whispers and shouts. And they suffer from gender muteness: they are unable to speak about gender they do in their daily practices.

Research on gendered practices demands sensitivity and readiness to make yourself a part of a common learning process with the people you study. From the researchers this has required a conscious effort to see the common cultural walls that enclose them as well others. Gender neutrality may be a special difficulty in the Nordic cultural context, but certainly not only there. It is connected to the avowed ideology of equality and the belief that our societies already have achieved full gender equality. An important cultural background is the common traditional reluctance to make gender a basis of conflict: 'women and men should act together, not oppose each other.' Do not quarrel. Don't be a troublemaker to the male elite is one valid interpretation but even Little Red Riding Hood cannot understand why her wish to get herself 'a little bit of air' should cause a quarrel. After all, it is a question of her life.

\section{Literature}

Balbo, Laura (1987) 'Crazy Quilts: Rethinking the Welfare State Debate from a Woman's Point of View', pp. 45-71 in Showstack Sassoon, Anne (ed.) (1987): Women and the State - The Shifting Boundaries of Public and Private. Hutchinson, London.

Tikkanen, Märta (1986) Punahilkka. WSOY, Juva. 